\title{
Industrial constructive system of civil buildings of increased survivability
}

\author{
Nataliya Fedorova ${ }^{1, *}$, Ashot Tamrazyan ${ }^{1}$ and Pavel Korenkov ${ }^{2}$ \\ ${ }^{1}$ Moscow State University of Civil Engineering, Yaroslavskoe shosse, 26, Moscow, 129337, Russia, \\ ${ }^{2}$ Academy of Construction and Architecture «V.I.Vernadsky Crimean Federal \\ University» Simferopol, Russia
}

\begin{abstract}
The paper considers a new industrial constructive system of residential and public buildings that meets modern requirements for protection against progressive collapse, improved spaceplanning, architectural and thermal protection solutions. The presence of a significant number of enterprises with technological lines for the production of structures for large-panel housing construction and their share in the market, combined with a number of shortcomings of the technical and space-planning solutions used, indicate the need to modernize these enterprises for their production to meet modern requirements. The purpose of this study was to develop an industrial constructive system of civilian buildings with increased resistance to progressive collapse, the production of which would not require expensive modernization of the construction industry enterprises. Based on the level calculation schemes, an algorithm is proposed for calculating such a system for a particular emergency impact. Numerical studies have established the correspondence of the developed constructive system to the requirements of a special limiting state under design loads and accidental effects caused by the disconnection of the vertical bearing from work.
\end{abstract}

\section{Introduction}

The development of new types of constructive systems of residential and public buildings that meet modern challenges remains one of the urgent problems of modern construction $[1,2]$. From the standpoint of reducing the time required for the construction of objects and reducing their material consumption, the technological systems of civilian buildings made of the reinforced concrete elements of large-panel house building are considered to be the most effective and most widely used [3-7]. At the same time, such systems for mass construction contain a number of significant design flaws: They have "rigid" spaceplanning schemes with limited room sizes; monotonous plastics of facades, low level of

*Corresponding author: FedorovaNV@mgsu.ru 
protection from special, including emergency effects (due to the use of only one-sided constructive links). On the other hand, the country has a significant number (over 250) of house-building enterprises with technological lines for the production of structures for mass large-panel house building, which in the total volume of housing construction in many regions of the country make up 50-65\% or more [8]. In this regard, the improvement and creation on this basis of new industrial constructive systems of buildings with enhanced protection against progressive collapse for mass construction is a current trend.

\section{Methods}

The aim of the presented work was the creation of a new industrial structural system of residential and public buildings of mass construction with enhanced protection against progressive collapse, improved space-planning schemes and high capabilities of thermal protection solutions and architectural expressiveness of facade systems of buildings. The research tasks included the development of proposals for a new industrial structural system for residential and public buildings, the development of an algorithm for calculating the stress-strain state of such structural systems with special accidental effects and conducting numerical studies to assess the redistribution of power flows in these systems.

\section{Results and Discussion}

The proposed structural system includes (Figure 1) supporting longitudinal and transverse wall panels-frames 1, interconnected in height by connecting elements 2 at least in two places in height, self-supporting internal 3 and external walls 4, supported by supporting L shaped cross-section beams 5 with a shelf width equal to the wall thickness and having thermal connectors in the form of holes with insulation arranged along the length of the shelf.

Bearing wall panels of the building are made in the form of panels-frames, the upper shelf of the assembled part of the bolt of which has reinforcement outlets 6 for connection with the reinforcement of the conforming it monolithic part. The floor slabs 8 have keys 9 . Reinforcement cages 11 are installed in the space between the side surfaces of the adjacent plates and the volume of this space is filled with fine-grained cementitious concrete 7.

The racks of the frame panels 1 are mounted on the upper surface of the monolithic part 10 of the assembled monolithic bolt (Figure 2) and using centering fixtures 12 or centering nests of the platform [9-11] or plug-in interface [12] are connected to the outlets of reinforcing bars 13 racks of the lower panel-frame using bathtub welding, threaded or crimp connections 14. In the rack of the panel in the area of the described platform joint, indirect fittings 15 are installed.

The crossbars of the wall panels are connected to the floor slabs with concrete, monolithic according to the release of reinforcement and using the keys on the side surface and the ends of the floor slabs. The external self-supporting wall is in the form of a threelayer structure, with an effective filling of the volume in the plane of the frame panel. Anteroom and anteroom partitions are made of light wall easily utilizable material with high thermal and sound insulation properties. The filling of the void volume of the thermal connectors of the bolts is made by a heat-insulating material with a low water absorption coefficient (for example, foam glass [13]), which ensures high thermal protection of the exterior walls of the building. In addition, the installation of load-bearing crossbars with thermal connectors along the outer contour of the building allows not only to provide thermal protection of the building, but also increases its overall spatial stability with special, including accidental effects. The solution of the same problem is also facilitated 
by the mutually perpendicular arrangement of the disks of the floor slabs above the adjacent rooms of the building (see Figure 1, b).

The connection of the frame racks with the help of reinforcement and centering gaskets ensures the transfer of compressive forces from the overlying rack to the underlying crossbar belt in the type of platform interface. The provided installation of additional reinforcing bars 16 at the end of the rack and bending them into the concrete body of the monolithic part of the bolt (see Figure 2) is aimed at ensuring the protection of the building frame from progressive collapse. In the event of a sudden shutdown of one of the columns from the frame of the building, the redistribution of power flows occurs and the crossbars above this column, together with the columns located above these crossbars, form a closed frame-rod spatial system that receives the forces from the changed power flows.

The reinforcement struts of the frame and precast-monolithic crossbar determined by calculation so that the sudden shutdown of one of the columns of the first floor of the building for a continuous bolt on the column and located above columns, provided the requirements of bearing capacity in special limit conditions [14-16].
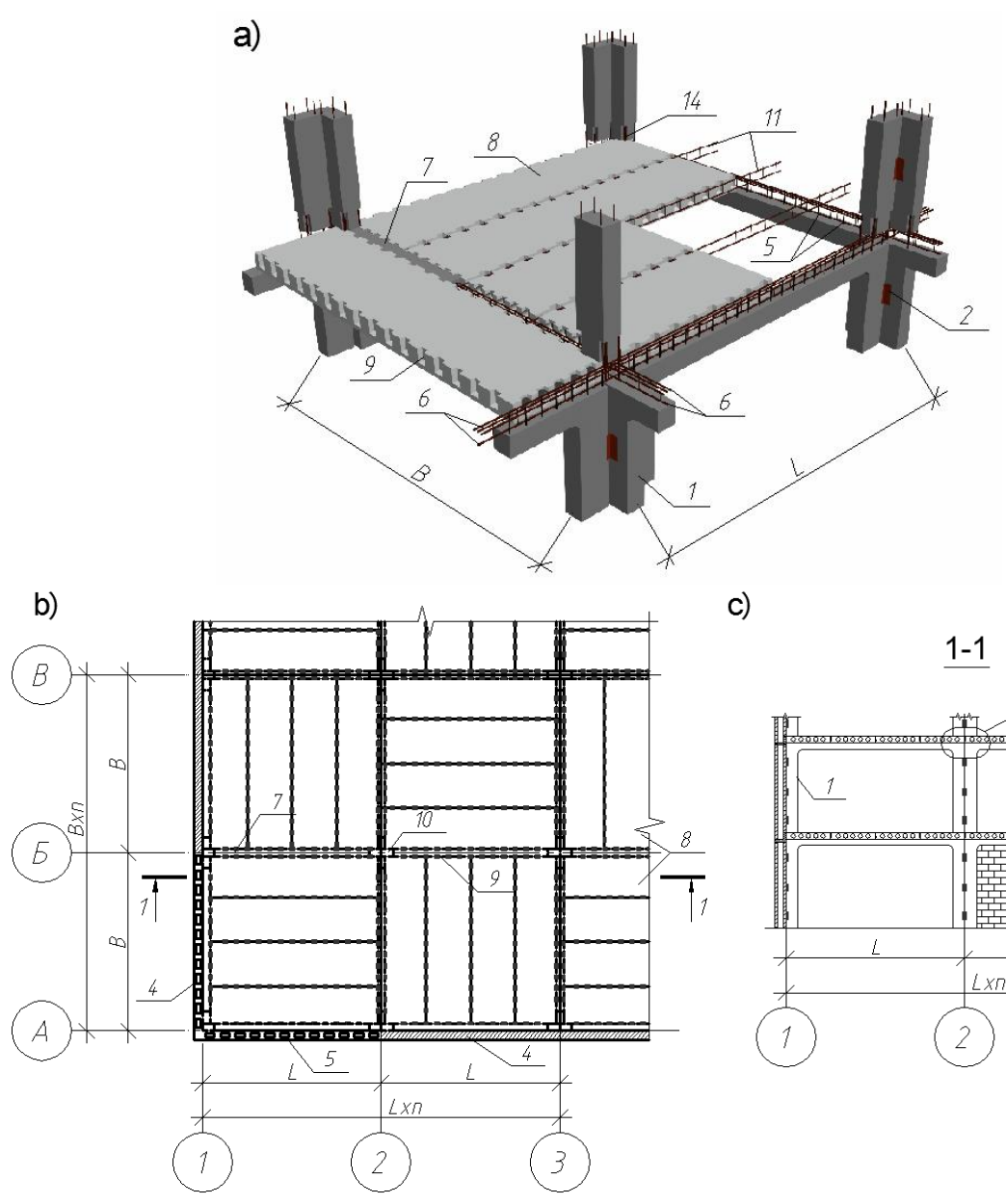

c)

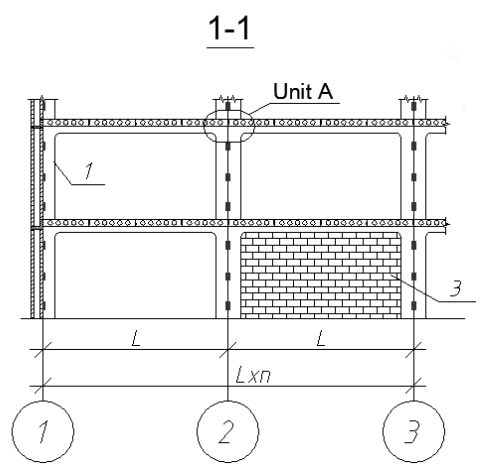

Fig. 1. Layout of the bearing elements of the structural system a- general view b- in plan, c- in section 


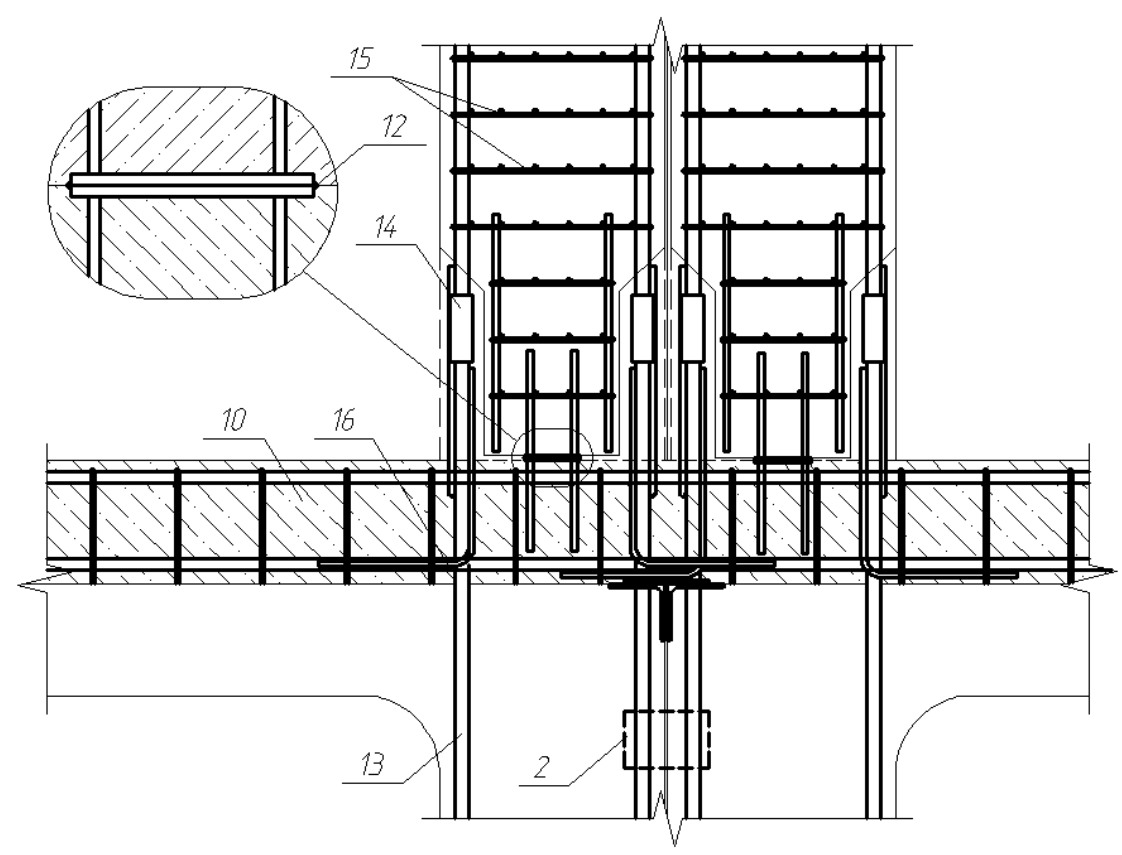

Fig. 2. Precast-monolithic joint of frame elements (Unit A)

\section{Features of algorithm of calculation of frame buildings.}

The calculation of the frame building of wood frame elements in the design load under domestic [17,18] and European standards [19] norms is performed on the settlement schemes of various levels. A design scheme of the first level (primary design model) models the whole building, including the Foundation, ground base [15]. A design scheme of the second level simulates the typical fragment - substructure $[14,20]$ the frame structure composition, which includes on and off column. The result of the calculation are the load, displacement and area of required reinforcement panels-frames including precastmonolithic design of beams, slabs, strapping girders and foundations.

The calculation of the frame building with the purpose of protection against progressive collapse is performed on special effects specified in the standards [14,15] as a sudden failure of the structural system of the building one of the supporting structures, for example the extreme contour of the building or the corner column of the ground floor. In this case, it is used to calculate the so-called secondary design scheme [14], which differs from the primary design scheme in that it removed one of the supporting structures. Since the sudden removal of this design of building structural system receives loading dynamics [16, 25], when calculating the required accounting. Experience of calculation of building frames considering loading dynamics [1, 21-23] showed that for complex objects, even with the use of high-performance software systems, such calculations are quite time consuming not only in time but also cause considerable difficulties for engineering analysis of the obtained results. In these works and also when on the basis of experimental data [22-24] have demonstrated the possibility of applying two and even three-level design of circuits to meet special influences, and in many cases, it is enough applied in the engineering practice, the kinematic method of limit equilibrium $[1,26]$.

Secondary design scheme for building frame first level, modeling the whole structural building framework includes a finite element model of all the main load-bearing structures of the building with a remote column of the first floor of the building (figure 3,a). The efforts of the eccentric compression in the remote column of $\mathrm{R}$ obtained in the primary 
design scheme, from the operational load in the secondary calculation scheme applied in the direction of a remote stand with the opposite sign. The calculation result of the secondary design scheme are load and displacement obtained all structural elements of a building framework after removal of the column.

Criteria for the evaluation of the possible local structures in the area off columns of the structural system of the entire building frame is allocated and constructed substructure secondary design scheme of the second level. Dimensions of the substructure and, accordingly, the design scheme is determined based on the size of local defects which is in accordance with [14] should be taken into account at calculation of bearing structures of one floor of the building on the site, the limited range with a minimum size of $28 \mathrm{~m} 2$ (diameter $6 \mathrm{~m}$ ) for buildings up to $75 \mathrm{~m}$. In accordance with the size of the substructure frame of the building to build a secondary design scheme of the second level are accepted within two spans: one span in each direction remote from the column (see figure 3).

Calculation of secondary design scheme is made on the normative values of loads with a safety factor for load equal to one. Mode is described loading of the substructure operating loads gij, $\mathrm{Nji}$, Mji and emergency exposure Rji is shown in figure 3,b. The strength of concrete and reinforcement will be accepted according to the normative values. Taking into account the dynamic nature of the special effects on the building structure, the first half wave of the oscillations of the frame of the building enter the factor of increasing the dynamic strength of concrete and steel [25].

\section{An example implementation of the described algorithm.}

Considered a fragment of a three-story frame public buildings from prefabricated elements with a grid of columns $5.2 \mathrm{~m}$ and a floor height of $3.6 \mathrm{~m}$ Section of the columns taken 200x300 mm. Reinforcement of columns As=As' taken 4 rods with a diameter of 14 $\mathrm{mm}$, class A400. Cross section precast beams made t-height $\mathrm{h}=470 \mathrm{~mm}$, width $\mathrm{b}=80 \mathrm{~mm}$ and a flange width $b^{\prime}=200 \mathrm{~mm}$ (see figure 3). The working reinforcement pins made of four rods of diameter $16 \mathrm{~mm}$ class A500. The class of concrete panels frames B30. Operating load is assigned in accordance with [13] as for public buildings with a reliability coefficient of responsibility $\gamma \_n=1$.. The impact of discarded panels of adjacent frames for the structural system of the building frame have been considered by the reactions in remote relationships in the level of the connecting elements (see figure 3,a). The loading regime adopted by the scheme of figure $3, \mathrm{~b}$. In this case, the phase $0-\mathrm{t}$, the loading operating loads were considered short-term static for three minutes after the loading operating loads produced by exposure ( $\mathrm{t} 1-\mathrm{t} 2)$ for one minute and then the loading dynamic by removing the middle column of the substructure (application of reaction R) for $0,04 \mathrm{sec}$. This mode is the static-dynamic loading frame and truss structural systems of reinforced concrete were determined according to test results [23]. However, the dynamic strength of concrete Rbd and reinforcement Rsd calculated according to the recommendations [25].

Analyzing the obtained results (figure 4) include the following. The increment of stresses in the compressed concrete after removal of the Central column in the most stressed cross-section bolt $1-1$ was $0.96 \mathrm{Rbd} / \mathrm{Rbd} 0,29=3.31$ times (see Fig.4,a). The maximum stress in the concrete was 0.96 its dynamic strength at time of loading $\mathrm{t}=0,04 \mathrm{sec}$. The increment of the voltage in the working armature pins in the same cross-section amounted to $0,93 \mathrm{Rsd} / \mathrm{Rsd} 0,2=4.65$ times, and did not exceed the dynamic strength of reinforcing steel class A500. Voltage in the armature of the compressed columns of the second floor in section 2-2 to remove the underlying columns of the first floor was 0.11 Rsd, and after removal of this column has changed the sign of these stresses and their values was 0.52 Rsd.

Analysis of the obtained quantitative values of the stress state in the beams and columns of the considered fragment of precast - monolithic frame of the building before and after the 
impact of emergency allows to note that the proposed design solution for the connection of rebar rack panel frame with fittings stand the underlying frame and anchoring a monolithic part of the crossbars optional rods 16 (see figure 2) rack frames of the second floor, provide protection for the considered frame of the building from the progressive collapse in case of sudden removal of one of the columns of the first floor.

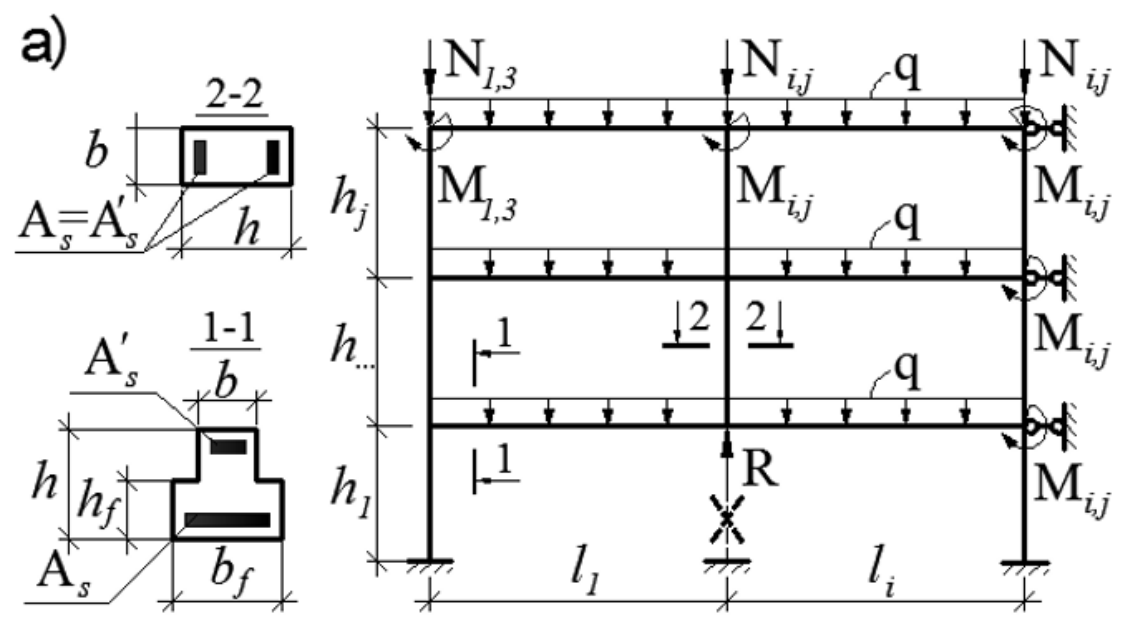

b)

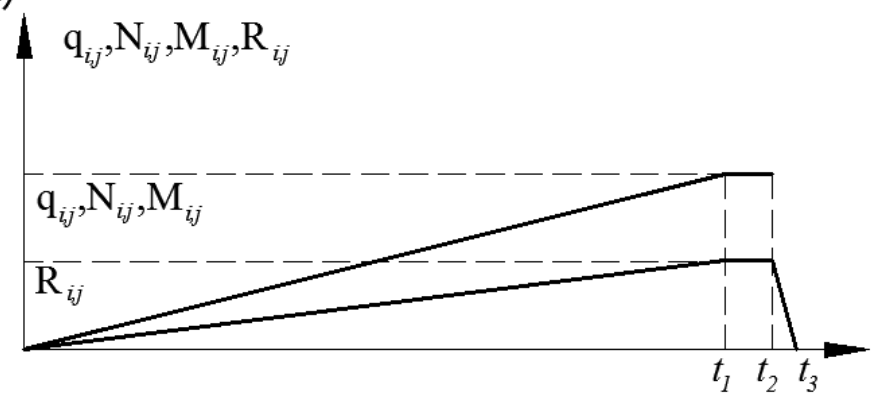

Fig. 3. A design scheme of a fragment of the substructure of the building frame (a) and scheme of its loading (b) 
a)
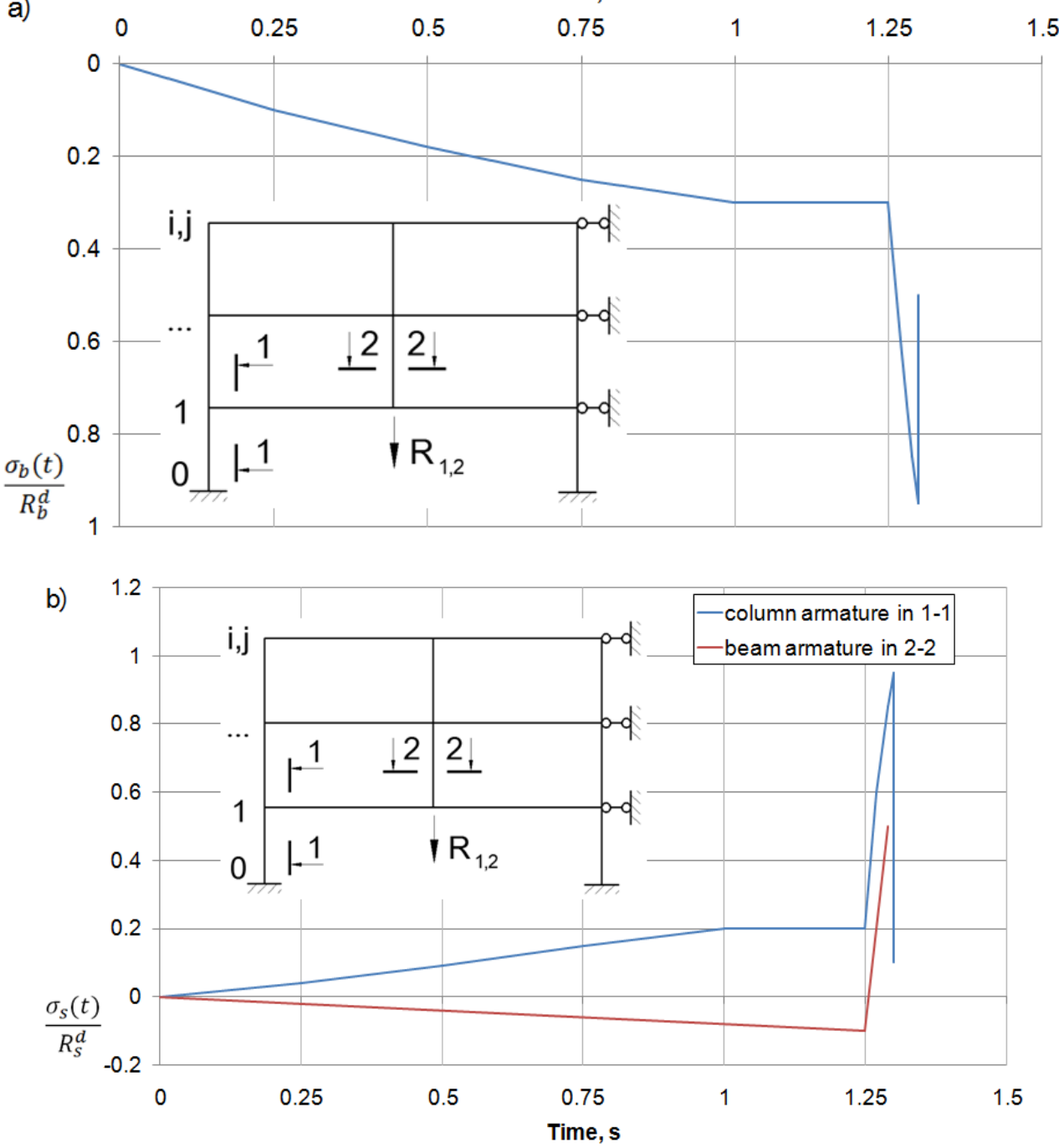

Fig. 4. Analysis of the deformation of compressed concrete (a) and tensile reinforcement (b)

\section{Conclusion}

An industrial structural system of a prefabricated monolithic frame of a multi-stored building made of reinforced concrete panel-frame elements providing new quality indicators of space-planning solutions, "plasticity" of facades, adaptability to special emergency impacts, high economic and environmental indicators for industrial buildings of mass use have been proposed. An algorithm has been developed for calculating the frameworks of buildings of this type in out-of-limit states caused by an accidental impact, in the form of a sudden shutdown of one of the supporting structures. Numerical calculations of the frame of the building of the panel-frame elements showed that the proposed design and platform reinforcement scheme the junction of the racks of the frame panels with the overlap girders provides for the requirements of the limiting states at design loads and the special influences considered. 
«This work was partially supported by the V.I. Vernadsky Crimean Federal University Development Program for $2015-2024 »$.

\section{References}

1. Zenin S.A., Sharipov R.Sh., Kudinov O.V., Shapiro G.I., Gasanov A.A. ACADEMIA. Arhitektura i stroitel'stvo, 2016, No. 4. Pp. 109-111 (rus)

2. V.I. Travush, V.N. Ponomarev, V.M. Bondarenko, K.I. Eremin Arhitektura. Stroitel'stvo. Obrazovanie, 2014, No 2, Pp. 7-16. (rus)

3. Nikolaev S.V. Zhilishhnoe stroitel'stvo, 2013, No 8, Pp. 2-9. (rus)

4. Klyuyeva N.V., Kolchunov V.I., Rypakov D.A., Buhtijarova A.S. Zhilishhnoe stroitel'stvo, 2015, No 5, Pp. 69-76. (rus)

5. Tamrazyan A., Filimonova E. Applied Mechanics and Materials. 2014. T. 467. C. 404409.

6. Tamrazyan A.G. Procedia Engineering. 2016. T. 153. C. 715-720.

7. Koyankin A.A., Mitasov V.M. Magazine of Civil Engineering. 2017. No 6. Pp. 175184. doi: 10.18720/MCE.74.14

8. Nikolaev S.V. Zhilishhnoe stroitel'stvo, 2018, No 3, Pp.3-8 (rus)

9. Pat. № 2627524. Russian Federation, IPC E02B1/61. N.V. Kljueva, P.A. Koren'kov, zajavl. 11.12.2015; opubl. 8.08.2017, Bjul. No 22. -8 p. (rus)

10. Pat. No 2506385 Russian Federation, IPC E04H 1/00. V.A. Il'ichjov, V.I. Kolchunov, N.V. Kljueva, A.S. Buhtijarova, zajavl. 1.08.2012, opubl. 10.12.2014, Bjul. No 4. - 8 p. (rus)

11. Kolchunov V.I., Osovskih E.V., Fomichev S.I. Zhilishhnoe stroitel'stvo, 2009,№12, Pp 12-16 (rus)

12. Sokolov B.S., Troshkov E.O. Zhilishhnoe stroitel'stvo. 2017. No 7. Pp.41-46 (rus)

13. Min'ko N.I., Puchka O.V., Evtushenko E.I., Narcev V.M., Sergeev S.V., Fundamental'nye issledovanija, 2013, No 6. - Pp.849-854 (rus)

14. SP 385.1325800.2018 JeS NTI "Tehjekspert", 2017. - 35 p.(rus)

15. GOST 27751-2014. Standartinform, 2015. - 13 p.(rus)

16. Kolchunov V.I.,Savin S.Yu. Magazine of Civil Engineering. 2018. No 4 . Pp.73-80. doi: 10.18720/MCE.80.7.

17. SP 296.1325800.2017. CPP, 2011. - 23 p.(rus)

18. SP 20.13330.2011. CPP, 2011. - 80 p.(rus)

19.17.EN 1991-1-1 Eurocode 1: Actions on structures - Part 1-1: General actions Densities, self-weight, imposed loads for buildings

20. Droogné D., Botte W., Caspeele R. Engineering Structures, Volume 160, 1 April 2018, P. 56-70 doi.org/10.1016/j.engstruct.2017.12.052

21. Min (Max) Liu , Akbar Pirmoz. Engineering Structures. Volume 123, 15 September 2016, P. 372-378 doi.org/10.1016/j.engstruct.2016.05.020

22. Min Liu.. Engineering Structures. Volume 48 March 2013 P. 666-673 doi.org/10.1016/j.engstruct.2012.12.011

23. Fedorova, N. V., Korenkov P. A. Promyshlennoe i grazhdanskoe stroitel'stvo. - 2016. №11. - Pp.8-13. (rus)

24. E. Masoero, P. Darò, B.M. Chiaia. Engineering Structures/ 54 (2013) P. 94-102 Doi: 10.1016/j.engstruct.2013.03.053\}

25. Kolchunov V. I., Kljueva N. V., Androsova N. B., Buhtijarova A. S. Moscow:ASV, 2014. 208 p. (rus)

26. LjubomirskiN. V. j, Rodin S. V., Koren'kov P. A., Abseljamov R. S. Stroitel'stvo i rekonstrukcija. 2014. No 5 (55). - Pp.38-46. 